\title{
Why are we trying to reduce length of stay? Evaluation of the costs and benefits of reducing time in hospital must start from the objectives that govern the change
}

\author{
Aileen Clarke
}

\section{Introduction}

In many different countries, those responsible for the care of patients in hospital are under some degree of political and managerial pressure to keep length of stay to a minimum. In the United Kingdom, for example, length of stay is one of the Health Service indicators on which some managers' performance related pay depends.

It is known that patients admitted for treatment with the same condition may experience considerable variation in length of stay. And it is also widely held that reductions of time spent in hospital will reduce costs without compromising patient outcomes. What are the implications of this, and what exactly is the basis for it?

It is not difficult to see why reduction in stay is a frequent focus for managerial attention. The concept is an accessible one; and progress in such a reduction can be measured relatively easily. Furthermore, the alternatives are fraught with difficulty. Most managers are aware that action on their part to encourage other improvements in a service-for example, through increasing clinical effectiveness-may be seen as an attempt to infringe clinical freedom.

Clinicians have their own reasons for holding the view that it is desirable to reduce time spent in hospital. There is a tradition of rather dire warnings about the dangers of a long stay in hospital. Often length of stay is seen to be synonymous with bed rest. For example, Asher as early as $1948^{1}$ said, "Beneath the comfort of the blanket there lurk a host of formidable dangers." An editorial in the $B M \mathcal{F}^{2}$ a year later put forward much the same view, and in 1960 in an article in the Lancet entitled "Hotels or hospitals?" Stallworthy ${ }^{3}$ berated London teaching hospitals for their variability in length of stay and pointed out the reduced throughput that this implied. Similar articles have appeared since that time, and a recent newspaper article described the substantial reduction in time spent in hospital as a result of realisation by the medical profession that bed rest "lowers morale and causes insomnia and constipation". 4

The aims of this review are to describe variation in length of hospital stay (particularly in relation to surgical procedures), along with currently available explanations for that variation; and to examine its relation to health outcomes and costs. In particular, the review considers four questions:
- What determines length of stay?

- Does length of stay make a difference to patients' health outcomes?

- Do reductions in length of stay really save money?

- Should we be trying to reduce length of stay?

\section{Methods used in this review}

A systematic Medline search was undertaken for references to length of stay occurring in the title or abstract of published work in English between 1983 and 1995. References were included if they: (a) fell into the relevant time period; $(b)$ referred to acute inpatient care.

They were excluded if they: (a) referred exclusively to length of stay as a proxy outcome variable where there was a main intervention of interest-for example, the use of a new drug or surgical technique; (b)referred to length of stay as only a part of a hospital stay-for example, intensive care or in some kind of rehabilitation facility; (c) were related exclusively to psychiatric diagnoses; or $(d)$ used a case series in one institution as the only study design.

Relevant medical literature before 1983 and unpublished sources were included. There are many papers on length of stay, perhaps reflecting its perceived importance in current thinking in health services particularly as a proxy measure of outcome. Much of the literature and research in this field is North American. There are few randomised trials, so much of the work is non-experimental, observational, and used large data sets. This review is to a certain extent selective as many of the examples to illustrate points are drawn from studies of surgical procedures. I have reviewed the quality of the evidence of each publication where relevant.

Variation in length of stay: broad patterns DOWNWARD HISTORICAL TRENDS Length of stay in hospital has decreased systematically over the past 20 years, both overall and for most conditions (table 1)..$^{5-9}$ The factors contributing to this downward trend are not necessarily those that might be assumed at first - for example, a response to research showing that a shorter stay is as efficacious as a longer one. There is, in fact, little research on the subject.

It might be assumed too that technological advance lies at the heart of the reduction of time spent in hospital. But there is evidence 
Table 1 Summary of studies investigating change in length of stay over time

\begin{tabular}{|c|c|c|c|}
\hline Patients & Years studied & $\begin{array}{l}\text { Drop in length } \\
\text { of stay }\end{array}$ & Comments \\
\hline $\begin{array}{l}\text { Surgical patients } \\
\text { only }^{5}\end{array}$ & $1965-86$ & $\begin{array}{l}8.2 \text { to } 6.6 \\
\text { days }\end{array}$ & \\
\hline All acute care ${ }^{5}$ & $1968-87$ & $\begin{array}{l}8.5 \text { to } 6.4 \\
\text { days }\end{array}$ & \\
\hline $\begin{array}{l}\text { Acute care in } \\
\text { Massachusetts }^{6}\end{array}$ & $1982-6$ & $\begin{array}{l}99 \text { to } 7.5 \\
\text { days }\end{array}$ & $\begin{array}{l}20 \% \text { Of the decrease occurred with } \\
\text { the onset of prospective payment } \\
\text { system. }\end{array}$ \\
\hline $\begin{array}{l}\text { Ocular trauma in } \\
\text { Maryland }^{8}\end{array}$ & $1976-86$ & $\begin{array}{l}6.1 \% \\
\text { reduction }\end{array}$ & \\
\hline 86 Most frequent $^{9}$ & $1980-6$ & $\begin{array}{l}34 \% \\
\text { reduction }\end{array}$ & $\begin{array}{l}\text { The greatest decreases of } \geq 85 \% \text { were } \\
\text { found for postmenopausal bleeding, } \\
\text { benign breast neoplasm, or excessive } \\
\text { menstruation. There was a decrease } \\
\text { of } 72 \% \text { in length of stay for hernia } \\
\text { repair. }\end{array}$ \\
\hline
\end{tabular}

that technological advance may in fact have conflicting effects. In one study, for instance, medical admissions were compared in 1961-2 with admissions in $1981-2 .{ }^{10}$ The authors found that length of stay decreased strikingly over time. They considered that some of the decrease might have been due to new techniques encouraging brief admissions for a specific diagnostic test-for example, cardiac catheterisation-which were not previously available. But in a similar study comparing admissions in 1972 and 1982, length of stay increased for two conditions in which the authors had found that the use of technological intervention had increased (infant respiratory distress syndrome and kidney transplantation). ${ }^{11}$

So, what factors do seem to figure most prominently in the overall reduction in a patient's time spent in hospital? In one study, researchers used multivariate analysis to apportion an estimated decrease in number of days in hospital over 10 years to several different factors. ${ }^{9}$ Historical trends in surgery were found to be the most important variables in that year, accounting for $80 \%$ of the decrease in length of stay in hip replacement and more than $100 \%$ of the decrease in coronary artery bypass grafting.

\section{GEOGRAPHICAL VARIATION}

The time patients with exactly similar conditions are likely to spend in hospital after any given treatment depends on the country, the region, the hospital, and the specialty. This kind of variation would suggest that patients' needs may not be the overriding factor in the decision over how long they stay in hospital.

Figures 1 and 2 show differences in length of stay in different countries for the specific elective surgical interventions of hernia repair and cholecystectomy. ${ }^{12}$ A sample of nationally collected routine data indicates that in 1988 a person admitted for cholecystectomy in Italy was likely to spend twice as long in hospital as a person admitted for the same procedure in Norway.

Caution has to be exercised in making comparisons of this kind as different countries have different methods of recording and collecting data and different approaches to quality control. However, it does seem to be the case that the country in which patients have their operation is an important determining factor in their likely length of stay in hospital.

Figure 3 shows mean duration of stay in days (log transformed with $95 \%$ confidence intervals $(95 \% \mathrm{CIs})$ ) for hysterectomy for districts in one English region.

Resident based data are used, and the figure is likely to underestimate differences. Nevertheless, substantial differences exist. These figures are not adjusted for case mix but it is unlikely that the differences are due solely to case mix differences.

Oddly, it has been found that geographical differences are maintained as a person's time spent in hospital decreases over time. Thus length of stay in the north east of the United States has remained longer than in the west but both continue to fall..$^{1314}$

Similar regional differences have been found in studies in Europe. ${ }^{15-19}$ In the United Kingdom, variation was found ${ }^{2021}$ in age adjusted duration of stay between districts in two regions for cholecystectomy, appendicectomy, and inguinal hernia (excluding day case operations), although again the data were not adjusted for case mix. It seems that districts did not maintain the same rank so that in one district patients might have the longest stay for one procedure and the shortest for another.

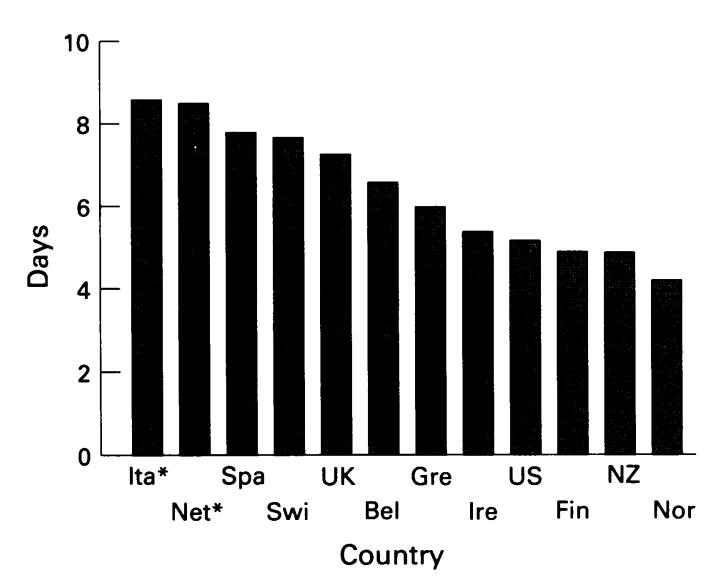

Figure 1 Mean length of stay for repair of hernia in 1987-8. Comparison between countries (Organisation for Economic Cooperation and Development (OECD) data 1993 except * 1987).

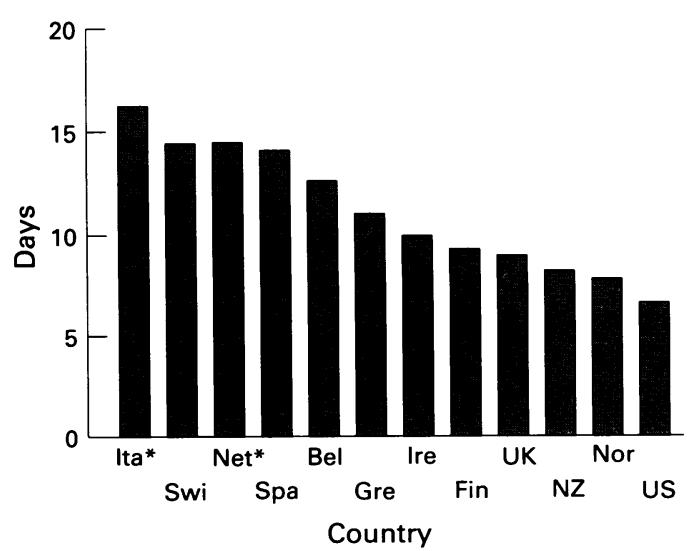

Figure 2 Mean length of stay for cholecystectomy. Comparison between countries (OECD data 1993 except * 1987). 


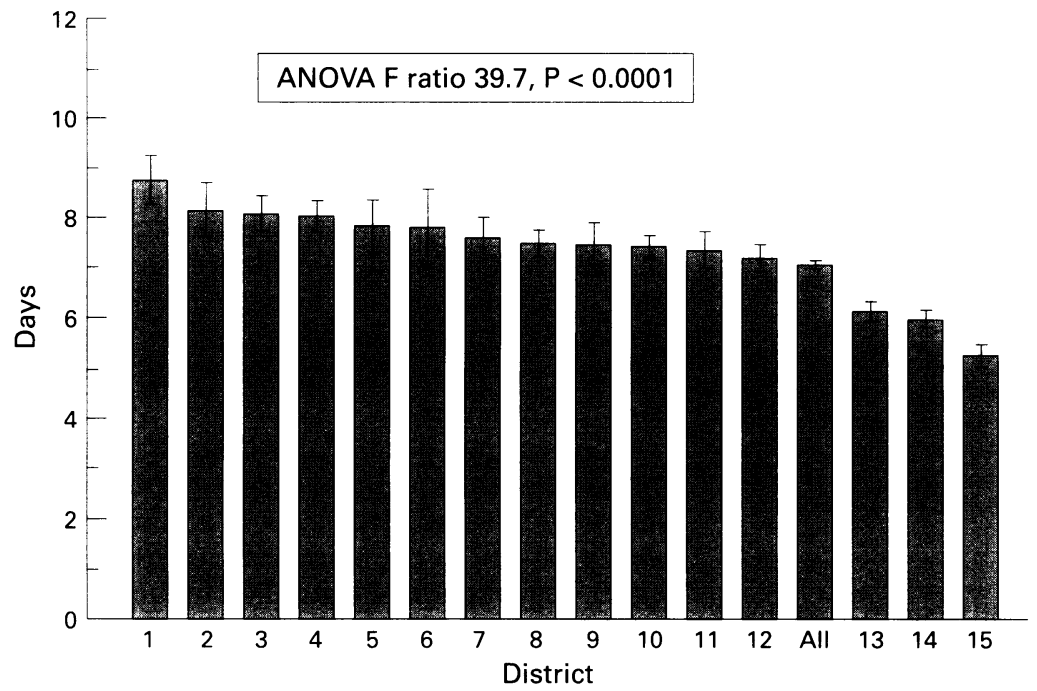

Figure 3 Mean length of stay (95\% CIs (log transformed)) for hysterectomy in district health authority residents. North East Thames Regional Health Authority data, 1992-3.

\section{What determines length of stay?}

The time that people spend in hospital might be thought to depend on circumstances related to the provider of care. Examples might include the individual practice style of a clinician, the locally available supply of beds, and method of payment (whether prepayment or fee for service). These are described as supply factors.

Alternatively, the time spent in hospital may depend primarily on issues related to patients' needs - for instance, measures of socioeconomic status, severity of disease, comorbidity, rate of recovery, or costs to the patient of a longer stay. ${ }^{22}$ These may be described as demand factors. The box summarises some of these factors.

\section{Causes of variation in length of stay Supply factors: \\ Individual practice style \\ Discharge policies; level of illness at which hospital care is considered desirable Bed supply, hospital competition, and the quality and availability of primary, community, or convalescent care \\ Method of payment - prepayment or fee for service \\ Demand factors: \\ Socioeconomic status \\ Disease severity \\ Comorbidity \\ Direct or indirect costs to the patient or their carers}

The importance of analysing and distinguishing between demand and supply factors lies in the implications for action within hospitals. If demand factors predominate in determining the length of stay, then probably little should or could be done to try to reduce variation between institutions. On the other hand, if supply factors are found to predominate, then this may point to a need to look at methods of practice and managerial constraints with a view to diminishing the variation in time spent in hospital.

Several authors in the United States have looked with multiple regression analyses on large aggregated routine data sets to disentangle the various characteristics associated with variation in length of stay. Routine data tend to cause a problem in allowing for adequate adjustment for case mix, and in particular for severity of illness and comorbidity, which are rarely well recorded routinely. This is a recurring theme in studies of a person's time in hospital and may contribute to the variability of many of the findings.

Assuming that adequate adjustment has been made for variation in case mix and in the quality of data sources, what are the main issues involved in the different supply and demand factors affecting duration of stay?

SUPPLY FACTORS

Individual practice style

It would seem likely that decision making behaviour of clinicians might be the chief determinant of length of stay when appropriate adjustments for case mix have been made. Working on this assumption, much effort has been directed towards changing clinicians' behaviour, particularly at the point of planning discharge. Studies assessing different methods of planning discharge sometimes found change in length of stay to be an important outcome but it has proved difficult to identify the exact nature of any cause. ${ }^{23}$

Other aspects of individual consultants' behaviour have been considered-for example, timing of ward rounds. The Audit Commission $^{24}$ has suggested that tolerance of uncertainty and perception of risk and probability may affect individual consultants' views on length of stay, but few publications support these views.

An analysis of several thousand hospital discharges in the United States ${ }^{25}$ showed that seniority affected length of stay, as over the academic year it declined by 0.43 days as junior doctors became more experienced.

However, there is some surprising but strong evidence from two different sources (The Netherlands and Wessex) to suggest that individual consultants do not determine length of stay, which for the patients of some consultants was found to be twice as long in one hospital as it was in another for the same condition after adjustment for case mix. ${ }^{15-18}$ Surprisingly, it has been suggested that there is a "when in Rome do as the Romans do" effect on consultants which determines their patients' length of stay in any given hospital.

This finding has been corroborated in one study, in which consultant physicians were unable to predict length of stay for elderly patients admitted to a department of general (internal) medicine. ${ }^{26}$

In short, individual consultants or senior medical staff may not be the chief determinants of the time their patients spend in hospital. It also seems that although junior hospital doctors can have some influence, this effect is unlikely to be responsible for the main regional and temporal differences that have been shown to exist. 
Bed supply

The effect of local availability of beds on length of stay has been investigated in several studies. One large study on regional variations in The Netherlands suggested that the strongest determinant was bed supply and quoted Roemer's law "a built bed is a filled bed." 2728 This was corroborated by another well designed study in The Netherlands. ${ }^{15}$

In the United Kingdom the picture is similar, ${ }^{29}$ with the additional finding ${ }^{18}$ that patients who had been longer on waiting lists had shorter stays because of increased pressure on beds. They found that hospitals able to send patients to convalescent facilities or community hospitals did not keep their patients for a shorter time and this has been confirmed in other studies. ${ }^{15-28}$

In the United States, in one study ${ }^{30}$ the authors found differences between two areas in length of stay for several procedures. In the area with the highest numbers of local hospitals -the larger bed supply-they reported a stay $14.8 \%$ longer for total hip replacement, $6.9 \%$ longer for hysterectomy, and $16.9 \%$ longer for all diagnoses than in the area with the smaller bed supply when adjustment for population density, age, and case mix had been made.

Convalescent facilities increase supply, so if the above finding holds, convalescent facilities would be expected to be associated with an increased length of stay. Two studies in the United Kingdom, one on general (internal) medical and surgical patients, and another on patients with stroke have documented a longer stay for individual patients awaiting a place in either convalescent or rehabilitation facilities. ${ }^{3132}$ However, in neither of these studies was overall bed supply investigated or comparisons made with other districts with different access to such facilities.

By contrast, Morgan ${ }^{20}$ suggested that the reason for a shorter stay in some of the districts she studied seemed to be the ability to transfer patients out of acute wards either to other hospitals or to convalescent facilities. One district classified as having the shortest stay in the South East Thames region transferred $19 \%$ of patients with hernia and $20 \%$ with appendicectomy to another hospital or to convalescent units.

The balance of evidence, however, does suggest that in different cases and situations in Europe and the United States, supply of beds is the factor with the strongest association with length of stay-increased supply leads to a longer stay. ${ }^{15-18} 28-30$

\section{Method of payment}

Clearly, the method of payment is not yet such an important issue in the United Kingdom. However, it has been shown to be an important factor in the United States, where different research teams have found that patients in health maintenance organisations have significantly shorter times in hospital than those treated under fee for service plans. ${ }^{33-36}$ Patients in the United States in neighbouring hospital beds with the same illness may find themselves in hospital for different times simply because they have different health plans.

\section{DEMAND FACTORS}

Patients' rate of recovery

Ideally, a patient's needs, and particularly their speed of postoperative recovery, should be the main factors determining their length of stay, variations in which might reflect good care. ${ }^{36}$ However, major studies of the effects of factors which might be thought to relate to patients' individual needs do not seem to relate to length of stay. ${ }^{15-38}$

Complications can act as a confounding variable. A long stay may be more likely to result in complications such as infection acquired in hospital. On the other hand, complications may also increase stay, ${ }^{18}$ as the patient's state of ill health might preclude discharge at the usual or routine time.

\section{Costs to the patient}

The costs of the stay in hospital to individual patients are important factors. These might be time costs or the direct financial costs of staying in hospital. In particular, an assumption might be made that those who had a higher income would lose more money by having to stay in hospital longer. In fact, studies related to surgical procedures have shown that neither patients' income, socioeconomic status, nor sex seem to be associated with duration of stay after adjustment for case mix. $^{7-15}$

The picture is undoubtedly more complicated for complex and chronic medical conditions. ${ }^{3940}$ Unfortunately, thorough analysis has not been undertaken to investigate the different demand variables in these groups of patient.

BALANCE BETWEEN SUPPLY AND DEMAND There are complex explanations for the considerable variations that exist in length of stay in hospital after any given procedure. Supply factors are shown to have by far the greatest influence on how long patients stay in hospital. Bed supply and method of payment seem to have the strongest associations. The intervention of medical staff can have some effect but influence from this quarter is limited. Perhaps surprisingly, investigation of a variety of demand factors seems to suggest that patients may have the least influence of all.

\section{Does length of stay make a difference?}

Variation in stay can only be used as a measure of quality of care if it can be shown that it makes a difference to clinical outcome. This section of the review explores the relation of length of stay to different outcomes, including mortality, infection, and where appropriate recurrence of the original condition.

Publications on the effect of length of stay on clinical outcome are few and become rapidly dated as the stays become shorter over time. One of the most widely quoted pieces of research, and one of the very few randomised controlled trials in this area, was on the effects 
of shorter length of stay on the outcomes of repair of hernia and varicose vein surgery. ${ }^{41-43}$ Patients were randomised to receive either a short stay ( 48 hours) or long stay (six to seven days). The authors found no difference in clinical outcomes, specifically complications or recurrence. In 1996 almost all patients admitted for varicose vein surgery and many admitted for repair of hernia are treated as day cases. Continuing decreases in stay have diminished the usefulness of this trial.

Nevertheless the scientific literature suggests that there should be an expectation of variation in outcomes with duration of stay. In other words, sometimes patients might experience a worse outcome from a shorter stay or vice versa. For example, studies of wound breaking strength in surgical cases might suggest that there is a theoretical minimum period during which bed rest might be desirable. Hospital care may also protect patients from onerous household chores or adverse home circumstances. But complications such as the development of thromboembolic disease ${ }^{44}$ or the development of hospital acquired infection ${ }^{45}$ are said to increase with longer stay. Also, both relatives and patients may gain a great deal of pleasure from early discharge.

The Office of Technology Assessment in the United States undertook a review of this issue some time ago and found that there was some evidence that a shorter stay is associated with a trade off between a slightly higher rate of minor complications and small monetary savings. ${ }^{13-46}$ However, the complications labelled by the authors as minor, included chest and wound infection, haematoma, unexplained fever, thrombophlebitis, and wound discharge-none of which is likely to be viewed as minor by patients.

All the studies reviewed in this area by the Office of Technology Assessment ${ }^{47-49}$ lacked sufficient statistical power to detect differences in the outcomes under investigation. In particular, those studies on the effects of shorter stay in elective surgery had a less than $75 \%$ chance of discovering a $50 \%$ difference between short and longer stay groups in the incidence of postoperative complications. All concluded that early discharge was safe, although this could not be concluded reliably from their data.

More recently the relation between length of stay and outcome for six common conditions was investigated with a retrospective nonexperimental design. ${ }^{50}$ Patients were recruited from teaching hospitals in Massachusetts and California. The authors used a composite measure of functional status as one of the measures of outcome. Significant and important variations in length of stay were found which remained after adequate adjustment for case mix. However, practically no differences in outcome were found to relate to length of stay, and only $2 \%$ of the overall variance in functional status for the six conditions could be explained by it . Patients who stayed a shorter time in hospital after transurethral resection of the prostate or cholecystectomy showed significantly less satisfaction.
In another recent study of the effects of shorter length of stay on the outcome of elective abdominal hysterectomy no difference was found in various outcomes including patient satisfaction at 10 days, six weeks, and three months alter a short or standard length of stay. ${ }^{51}$

\section{RELATION WITH MORTALITY}

A routine data set of patient's abstracts covering 600000 patients admitted for acute care between 1970 and 1973 to 17 hospitals was investigated for any relation between length of stay and mortality in hospital. ${ }^{52}$ The researchers found a strong association after adjusting for diagnosis and severity. Patients with a longer stay had a higher than expected in mortality in hospital.

However, mortality as the outcome in this type of study is problematic for three reasons. Firstly, mortality is not the most appropriate outcome measure to examine the effectiveness of most treatments or procedures. Secondly, mortality in hospital may truncate what would otherwise have been a longer stay. Thirdly, a shorter stay may be associated with lower mortality only because patients discharged earlier may die outside hospital.

In summary, studies investigating the effects of length of stay on the outcomes of health care have three main problems. Firstly, few select the most appropriate outcomes. Secondly, outcomes chosen are often insufficiently frequent for differences in their occurrence to be reliably compared. Lastly, most studies fail to take sufficient account of differences in case mix. All studies reported, however, find no important effect of shorter stay on health outcome.

Although in two studies, on laparoscopic sterilisation and repair of inguinal hernia, satisfaction with day care was lower than with a longer stay, ${ }^{53-54}$ many studies of satisfaction have shown that most patients appreciate their time in hospital regardless of its duration. ${ }^{42-43}$ ${ }^{50-55} 56$ Currently, therefore, there is very little evidence of any relation between length of stay and outcome.

\section{Do reductions in length of stay really save money?}

Politicians and managers think that reducing the time spent in hospital will reduce costs per patient and therefore release capacity to treat more patients. This is the premise on which pressure to shorten stay is founded. In fact, very little research has been undertaken to examine overall costs and benefits of reduction in stay or the advantages of treating more patients per bed, per ward, or per year. What is known, however, is that a shorter stay is liable to increase overall costs if bed occupancy is kept at a constant level. Or to put it another way, shortening stay is liable to increase costs per day for the hospital. This is because for both medical and surgical patients, the main costs occur in the first half of the stay when input from staff, investigation, and intervention are at a maximum. Stays in hospital are almost always shortened by reducing lower depend- 
ency "cheaper" days, usually in the second half of the stay. This section of the review examines some of these issues.

\section{Who gains what from early discharge?}

In a valuable review of the economic issues surrounding shortening stay it has been suggested that there are several common fallacies associated with the widespread belief that there are substantial gains from early discharge. ${ }^{57}$ These fallacies include: the distribution of costs over length of stay is not an issue of great relevance. In fact each additional day of stay is not an adequate index of additional intensity or costs of services provided as has recently been shown for patients with total hip replacement in the United Kingdom. ${ }^{58}$

Another example of a common fallacy ${ }^{57}$ is that reduced length of stay causes negligible increases in primary and community care costs. There is a danger of underestimating both direct and indirect costs to patients-for instance, costs of attending preoperative investigation clinics or early postoperative follow up clinics. Many studies seem to have taken inadequate account of the costs to patients of shorter stay. The costs of caring at home might be estimated by attaching an average nursing wage to the time spent by a relative caring for a patient at home regardless of whether the relative is employed or not. ${ }^{57}$

A third common fallacy is that financial savings are used to improve patient care. Financial savings made by shortening a hospital stay, small as they might be, are never given to the patient to use on buying their own home care. Savings are invariably shared out over the totality of health care provided by the relevant provider and are usually used to admit more new patients to hospital.

In conclusion, it seems clear that evaluation of the costs and benefits of a shorter stay must start from the objectives that governed the change, ${ }^{57}$ and if these objectives were to reduce overall healthcare costs, then these are unlikely to be achieved.

An important study in British Columbia ${ }^{59}$ investigated the economic pay off of the introduction of paediatric day care. Children who were in hospital for longer had more investigations, and the use of day care made a saving of $60 \%$ over the use of inpatient facilities. But the authors also found that the introduction of surgical day care expanded the total amount of surgery performed on a static population of children. As they did not examine the appropriateness of the surgery either before or after the introduction of day care, either the children had previously been under supplied with surgical services and the expansion was therefore appropriate or the expansion represented an unnecessary increase in surgical intervention. A similar finding was found in New South Wales in Australia ${ }^{60}$ where patterns of use of hospital beds for hip fracture were examined. The authors found that between 1979 and 1990 there was a $45 \%$ increase in the total number of fractures but time in hospital had decreased, so the overall bed use in 1991 was similar to that in 1979 . Here there is no doubt about the appropriateness of hospital based care, but the costs to patients and community services of this shortening of stay were not examined and it is possible that they may have been considerable.

When paediatric day care was introduced ${ }^{59}$ no savings were found because day care added to, not substituted for, the inpatient care already provided. The authors concluded that this lack of substitution was because those who work in the hospital sector naturally have a strong incentive not to reduce length of stay to the point of allowing savings to be made by the closure of beds, wards, or hospitals because this implies reducing staff numbers.

So, all in all, are costs reduced by reductions in stay? And, if so, whose costs are reduced most? The short answers seem to be:

- The savings may seem to be small, as they are usually lost in the totality of healthcare expenditure and are not clearly identifiable

- Costs are borne most heavily by patients and their carers and have perhaps as yet not been adequately evaluated

The basic goal underlying reduction in stay should be to enable planned increases in effective and appropriate health care which could not otherwise be undertaken. Although this is clearly the potential overwhelming benefit of a reduction in stay, it is as yet unproved. The final question to be considered by this review involves exploring the practical implications of the findings so far.

\section{Should we be trying to reduce length of stay?}

It depends what the object of the exercise is. It is natural for managers to focus on standardising and shortening stay. After all, it is easy to get hold of information about length of stay, and fairly simple practical steps can be taken which will make an immediate difference to the pattern shown by individual hospitals. In short, variations in stay seem irrational and hence a worthy target for attention.

However, although the best methods for reducing the time spent in hospital are not clear from the research publications, ${ }^{29}$ over recent years there has been a reduction for several conditions. This has allowed for a continuing increase in the overall volume of work being undertaken. Few studies show firstly, how this increase in numbers of patients treated due to a shorter stay amounts to a planned response to a population's defined health needs for effective and appropriate care or secondly, that the associated additional direct or indirect costs to patients are acceptable to them.

It has been found that unless wards are closed, overall hospital costs are not reduced by shortened stay, instead, costs remain the same or increase because the number of patients treated is increased. Of course this increase almost certainly does have a positive benefit for patient populations, but this benefit may still not be the optimal achievable benefit because of the unplanned way the freed resources are used. The benefits of a person's reduced time in hospital are critically depend- 
ent on the effectiveness and appropriateness of the work which fills up the slack. So although there has been a strong drive to reduce this, both the economic and the health related advantages have not been clearly shown.

Whether reducing a patient's time in hospital is of benefit to the patients is unclear. Satisfaction of patients and their relatives may be related to length of stay and has been shown to be high for various types of day surgery. But it is possible that for different groups of patients either a longer or a shorter stay may increase satisfaction.

Perhaps most importantly, reductions in time spent in hospital have been shown to be safe as they have not been shown to have a major effect on health outcome (although there are methodological problems in almost all studies that have been undertaken to examine this relation).

So, should the effort to reduce stay be continued? On the one hand, it seems that a reduction is safe. On the other, there are many important unanswered questions. It is by no means clear who benefits from the continuing drive to decrease stay further, or exactly what those benefits are. In future the onus on those behind the drive to reduce length of stay should be to show that it is in the best interests of both individual patients and wider patient populations.

Although the views expressed are my own and any errors are my own responsibility, I would like to thank Nick Black, Marsailid Cameron, Sonja Ruehl, and John Hamm for their invaluable help and comments.

1 Asher RAJ. The dangers of going to bed. $B M \mathcal{F} 1947$ ii:867-8.

2 Editorial. Early rising after operation. BMF 1948;ii:1026-7.

3 Stallworthy JA. Hotels or hospitals? Lancet 1960;i:103-6.

4 Smith T. Bed rest. The Independent 1992;0ct 18:73.

4 Smith T. Bed rest. The Independent 1992;0ct 18:73. pokras R, Kozak LJ, McCarthy E, Graves EJ. Trends in hos-
pital utilization, 1965-86. Am f Public Health 1990;80: pital util

6 Epstein AM, Bogen J, Dreyer P, Thorpe KE. Trends in length of stay and rates of readmission in Massachusetts: implications for monitoring quality of care. Inquiry 1991;28:19-28.

7 Sloan FA, Valvona J. Why has hospital length of stay declined? An evaluation of alternative theories. $S o c S$ Med 1986;22:63-73.

8 Tielsch JM, Parver LM. Determinants of hospital charges and length of stay for ocular trauma. Ophthalmology 1990 97:231-7.

9 Rosevear GC, Gary NE. Changes in admissions, lengths of stay, and discharge diagnoses at a major universitystay, and discharge diagnoses at a major universityaffiliated teaching hospital: im

10 Steiner JF, Feinberg LE, Kramer AM, Byyny RL. Changing patterns of disease on an in-patient medical service 1961-2 to $1981-2$. Am $\mathcal{F}$ Med 1987;83:3315.

11 Showstack JA, Stone MH, Schroeder SA. The role of changing clinical practices in the rising costs of hospita care. $N$ Engl $₹$ Med 1985;313:1201-7.

12 Organisation for Economic Cooperation and Development. Health data. Paris: OECD, 1993.

13 Health technology case study 24. Variations in hospital length of stay: their relationship to health outcomes. Washington, DC: US Congress, Office of Technology Assessment, 1983. (OTAHCS-23.)

14 Gornick M. Medicare patients: regional differences in length of hospital stays. 1969-71. Social Science Bulletin July 1975. In: Health technology case study 24. Variations in hospital length of stay. Their relationship to health outcoms. hospital length of stay. Their relationship 20 health outcomes. Assessment, August 1983. (OTA-HCS-23.)

15 Westert GP. Variation in use of hospital care. Assen: Van Gorcum, 1992.

16 Heasman MA. How long in hospital? A study of variation in duration of stay for two common surgical conditions. Lan cet 1964;ii:539-41.

17 West RR, Roberts CJ. Some observations on the management of appendicitis in Wales. Int $₹$ Epidemiol 1974;3. 351-7.
18 Griffiths M, Waters WE, Acheson ED. Variation in hospital stay after inguinal herniorrhaphy. $B M F$ 1979;:787-9. Author, vol No

19 Gritfiths M, Waters WE, Acheson ED. Sickness absence after inguinal herniorrhaphy. $\mathcal{F}$ Epidemiol Community Health 1979;33:121-6.

20 Morgan $M$. Variations in length of stay at district level. In: Ham C, ed. Health care variations. Kings Fund Institute, 1988. (Research report No 2.)

21 Morgan M, Beech R. Variations in lengths of stay and rates of day case surgery: implications for the efficiency of surgical management. $\mathcal{F}$ Epidemiol Community Health 1990 44:90-105.

22 Burns LR, Wholey DR. The effects of patient, hospital, and physician characteristics on length of stay and mortality. Med Care 1991;29:251-71.

23 Marchette L, Holloman F. Length of stay, significan variables. $\mathcal{F}$ Nursing Admin 1986;16:12-9.

24 Audit Commission. Lying in wait: the use of medical beds in acute hospitals. London: HMSO, 1992.

25 Rich EC, Gifford G, Luxenberg M, Dowd B. The relationship of house staff experience to the cost and quality of

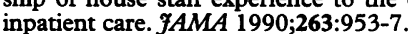

26 Asberg KH. Physicians' outcome predictions for elderly patients. Survival, hospital discharge and length of stay in a department of medicine. Scand $\mathcal{F}$ Soc Med 1986;14;12732.

27 Roemer MI. Bed supply and utilisation: a natural experiment. fournal of the American Hospital Association 1961; 35:34-42.

28 van Doorslaer EKA, van Vliet RCJA. A built bed is a filled bed: an empirical re-examination. Soc Sci Med 1989, 28:155-64.

29 Beech R, Withey C, Morris R. Understanding variations in lengths of stay between hospitals for fractured neck of femur patients and the potential consequences of reduced stay targets. $\mathcal{F}$ Public Health Med 1995;1 7:77-84.

30 Robinson JC, Luft HS, McPhee SJ, Hunt SS. Hospital competition and surgical length of stay. Fournal of the American Hospital Association 1988;259:696700.

31 Robbins JA, Donaldson LJ. Analysing stages of care in hospital stay for fractured neck of femur. Lancet 1984; ii:1028-9.

32 Wade DT, Hewer RL. Hospital admission for acute stroke who, for how long, and to what effect? $₹$ Epidemiol Community Health 1985;39:347-52

33 Johnson AN, Dowd B, Morris NE, Lurie N. Differences in inpatient resource use by type of health plan. Inquiry 1989;26:388-98.

34 Stern RS, Juhn PI, Gertler PJ, Epstein AM. A comparison of length of stay and costs for health maintenance organization and fee-for-service patients. Arch Intern Med 1989, 149:1185-8.

35 Bradbury RC, Golec JH, Stearns FE. Comparing hospital length of stay in independent practice association HMOs and traditional insurance programs. Inquiry 1991;28:8793.

36 Hadley J, Zuckerman S, Feder J. Profit and fiscal pressure in the prospective payment system: their impacts on hospithe prospective payment syst
tals. Inquiry 1989;26:354-65.

37 Simpson JEP, Cox AG, Meade TW, Brennan PJ, Lee JA Right stay in hospital after surgery: randomised controlled trial. $B M F$ 1977;i:1514-6.

38 Chen E, Naylor CD. Variation in hospital length of stay for acute myocardial infarction in Ontario Canada. Med Care 1994;32:420-35.

39 Johnston M, Wakeling A, Graham N, Stokes F. Cognitive impairment, emotional disorder and length of stay of elderly patients in a district general hospital. Br $¥$ Med Psychol erly patients in a
$1987 ; 60: 133-9$.

40 Maguire PA, Taylor IC, Stout RW . Elderly patients in acute medical wards: factors predicting length of stay in hospital BMF 1986;292:1251-3.

41 Adler MW. Changes in local clinical practice following an experiment in medical care: evaluation of evaluation. $f$ Epidemiol Community Health 1978;32:1436.

42 Adler MW, Waller JJ, Kasap HS, King C, Thorne SC A randomised controlled trial of early discharge for inguinal hernia and varicose veins: some problems of methodology. Med Care 1974;12:541-7.

43 Adler MW, Waller J, Creese A, Thorne SC. Randomised controlled trial of early discharge for inguinal hernia and
varicose veins. $₹$ Epidemiol Community Health $1978 ; 32: 136-$ 42.

44 Thromboembolic Risk Factors (THRIFT) Consensus Group. Risks of and prophylaxis for venous thromboembolism in hospital patients. BMF 1992;305:56774.

45 Broderick A, Mori M, Mettleman MD, Streed SA, Wenze RP. Nosocomial infections: validation of surveillance and computer modelling to identify patients at risk. $A m \mathcal{F} E p$ demiol 1990;131:734-42.

$46 \mathrm{McPherson} \mathrm{K}$. Length of stay and health outcome. $B M F$ 1984;88:1854-5.

47 Ruckley CV. Day care and short stay surgery for hernia. $\mathrm{Br} \mathcal{F}$ Surg 1978;65:14.

48 Morris D, Ward A, Handyside A. Early discharge after hernia repair. Lancet $1968 ; \mathrm{i}: 681-5$.

49 Russell I, Fell M, Devlin HB, et al. Day care surgery for hernias and haemorrhoids. Lancet 1977;i:844-7.

50 Cleary PD, Greenfield S, Mulley AG, Pauker SG, Schroeder SA, Wexler L, McNeil BJ. Variations in length of stay and outcomes for six medical and surgical conditions in Massachusetts and California. FAMA 1991;266:73-9. 
51 Clarke A, Black NAB, Rowe P. Does a shorter length of stay affect the outcome and costs of hysterectomy in southern England? $\mathcal{F}$ Epidemiol Community Health (in press)

52 Flood AB, Ewy W, Scott R, Forrest WH, Brown BW. The relationship between intensity and duration of medical services and outcomes for hospitalised patients. Med Care 1979;17:1088-102.

53 Michaels JA? Reece-Smith H, Faber RG. Case-control study of patient satisfaction with day-case and inpatien inguinal hernia repair. $₹ R$ Coll Surg Edinb 1992;37: inguinal

54 Thomas H, Hare MJ. Day case laparoscopic sterilization time for a rethink? Br f Obstet Gynaecol 1987;94:445-8.

55 Black NA, Sanderson C. Day surgery - development of a questionnaire for eliciting patients' experience. Quality in Health Care 1993;2:157-61.
56 Black NA, Petticrew M, Hunter D, Sanderson C. Day surgery development of a national comparative audit service. Quality in Health Care 1993;2:162-7.

57 Jonsson B, Lindgren B. Five common fallacies in estimating the economic gains of early discharge. Soc Sci Med 1980;14:27-33.

58 Hollingworth W, Todd C, Parker M, Roberts JA, Williams $R$. Cost analysis of early discharge after hip fracture. $B M \mathcal{F}$ 1993;307:903-7.

59 Evans RG, Robinson GC. Surgical day care: measurements of the economic payoff. Can Med Assoc F 1989;123: 873-88.

60 Lord SR. Hip fractures: changing patterns in hospital bed use in NSW between 1979 and 1990. Aust NZ $\mathcal{F}$ Surg 1993:63:352-5. 